\title{
Publicaciones recientes del Instituto de Investigaciones Estéticas
}

\author{
\$ \\ La danza contra la muerte \\ de Alberto D allal \\ Tercera edición, corregida y aumentada, 1993 \\ (M onografías de arte, 2). ISBN 968-58-0592-X
}

Los materiales reunidos en este libro, resultado de más de 20 años de observaciones e investigación, resultan atractivos por la diversidad de los temas tratados, la profundidad y pertinencia del análisis, la agilidad de su redacción y el conocimiento íntimo que sobre la danza tiene el autor, todo lo cual contribuye a hacer de esta obra una lectura a la vez amena e inteligente.

El libro, galardonado en 1979 con el Premio M agda Donato, y con mención honorífica del Premio Arnaldo Orfila a la Edición U niversitaria en 1993 , está dividido en tres secciones. La primera, teórica, se compone de temas de investigación. La segunda se ocupa del desarrollo histórico de acontecimientos, obras y personajes de la danza moderna mexicana. Por último, la tercera parte constituye un examen crítico de las figuras y grupos más destacados de la danza en M éxico y el mundo.

\author{
s
Guía del Archivo de la Antigua Academia de San Carlos.
Cuarta parte, 1867-1907
deEduardo Báez M acías

1993 (Estudios y Fuentes del Arte en M éxico, xxxvi),

2 vols. ISBN 968-36-3005-7

La cuarta parte de esta guía comprende la revisión de los archivos de la Academia de los años de 1867 a 1907 y los documentos del 6843 al 9995, cuya investigación inició el doctor Justino Fernández y que corresponden al tiempo de la República restaurada, a los gobiernos de J uárez y Lerdo de T ejada y a más de tres decenios del régimen porfirista, esto dentro del marco del quehacer de la Academia de San Carlos o de la Escuela N acional de Bellas Artes, pues como se informa cambió de nombre en I867 gracias a la Ley O rgá nica de Instrucción Pública para el D istrito Federal. Esta guía, de dos volúmenes, incluye un índice iconográfico y 32 fotografías relacionadas con documentos que constituyen el cuerpo principal de esta investigación. 


\author{
s \\ Protocolos I \\ de M ina Ramírez M ontes \\ 1993 (Catálogos de D ocumentos de Arte, 16). \\ ISBN 968-36-0000-0
}

dedicados al arte colonial. Los catálogos de documentos de arte pretenden apoyar la tarea de los historiadores del arte, facilitándoles el acceso a las fuentes primarias de información. El presente libro abarca la información contenida del volumen 9i6 al II85 del ramo Templos y conventos y que contiene información que va del siglo xviI al XIx.

\author{
\$ \\ Cine y sociedad en M éxico, \\ I896-1930; volumen II: \\ Bajo el cielo de \\ M éxico (1920-1924) \\ de Aurelio de los Reyes
}

I993. ISBN 968-36-3126-6

Éste es un libro de historia del cine, en primer lugar, luego de historia de M éxico durante los años de 1920 a I924, periodo en que la producción cinematográfica quedó claramente dividida en dos rubros: el documental educativo, patrocinado por el Estado, y la película de argumento, producida por los particulares. Bajo esta perspectiva, De los Reyes se propone mostrar cómo, a partir del cine, se pueden reflejar las consecuencias posrevolucionarias de las que escasamente hablan los libros de historia que abordan ese periodo, así como el porqué se filmaron esos acontecimientos. "H ablar de ellos - dice D e los Reyes- , me sirvió para mostrar diversos aspectos de la vida y sociedad de aquellos años."
La riqueza de los documentos presentados en los catálogos los ha convertido en una herramienta indispensable para el trabajo de los especialistas, sobre todo para aquellos 
今

\section{Arquitectura del porfiriato en M éxico \\ de Berta E. T ello Peón}

I994, 36 transparencias. ISBN 968-36-3509-I

\author{
La pintura de retrato en \\ el siglo $x I x$ \\ de Rocío Gamiño 0 choa
}

El trabajo se inicia con un planteamiento de la situación del país en los últimos años del siglo xix en todos los aspectos. Continúa con el urbanismo y obra pública que fueron de importancia especial en el porfiriato. Estas obras fueron destinadas a mejorar la sanidad del país, así como a crear una nueva imagen urbana.

Para el análisis de los edificios, éstos se agrupan de acuerdo con el uso que tuvieron: arquitectura pública, arquitectura habitacional y arquitectura religiosa. En cada una de estas divisiones se da una explicación de las características generales que hacen de esas construcciones un modelo de arquitectura porfirista. Se ejemplifica con algunos edificios que han sido representativos.
I994, 36 transparencias. ISBN 968-36-3505-

Este catálogo presenta un breve estudio de los pintores más relevantes en el género del retrato durante los últimos años del siglo xviri hasta la primera década del siglo $\mathrm{xx}$, así como la concepción de aquellos que estuvieron en la Academia de San Carlos, su manifestación en las escuelas de provincia y el inicio del modernismo. Lo ilustran obras de grandes artistas como Rafael Ximeno y Planes, Pelegrín Clavé, Juan Cordero, Felipe Gutiérrez, José Luis Rodríguez Alconedo, José M aría Estrada, Antonio Becerra Díaz, H ermenegildo Bustos, Julio Ruelas y Saturnino H errán. 